\title{
Willingness to pay for water and water rights definition: study among smallholder irrigators in Limpopo province, South Africa
}

\author{
S. Speelman ${ }^{1}$, M. D'Haese ${ }^{1}$, A. Frija ${ }^{1}$, S. Farolfi' ${ }^{2}$ \& L. D'Haese ${ }^{1,3}$ \\ ${ }^{1}$ Department of Agricultural Economics, Ghent University, Belgium \\ ${ }^{2}$ Centre for Environmental Economics and Policy in Africa and Cirad \\ GM Eau, South Africa \\ ${ }^{3}$ Faculty of Bio-science Engineering, University of Antwerp, Belgium
}

\begin{abstract}
Internationally there is growing understanding that water rights are important and that a lack of effective water rights systems creates major problems for the management of increasingly scarce water supplies. In South Africa the smallholder irrigation sector faces two major challenges. Firstly water use is inefficient and secondly government, which in the past invested huge amounts of money in the sector, targets improved cost recovery. Improving the definition of the water rights system can have a positive effect with regard to these challenges. At one hand improvements in the definition of water rights can stimulate smallholders to use water more productively, encouraging cooperation and investment; at the other hand an improved water rights system increases willingness to pay for water, allowing government to charge higher water prices and thus improve cost recovery. This study proposes contingent ranking to analyse the willingness to pay of smallholder irrigators for changes in the water rights system. Results indicate that smallholders are prepared to pay considerably higher water prices if these prices are connected with advancements in the water rights system. In a second step the sample population was stratified to evaluate the impact of smallholder characteristics on their willingness to pay. The importance attached to different dimensions of water rights clearly differs among groups. For example farmers suffering water shortages attach more importance to secure water supply. Policy makers can use such results to guide reforms in the design of water rights and to increase public support for interventions.
\end{abstract}

Keywords: contingent ranking, water rights, South Africa, willingness to pay, irrigation, efficiency. 


\section{Introduction}

Internationally there is growing understanding that water rights are important and that a lack of effective water rights systems creates major problems for the management of increasingly scarce water supplies $[1,2]$. If water rights are illdefined, this creates high transaction costs (information search, negotiation, monitoring) for making decisions over water use and therefore seriously impairs the efficient use of water [3]. This limits the value people assign to water [4, 5]. It however also implies that if water rights are better defined, people are willing to pay higher values for water use because the transaction costs are reduced $[6,7]$. The magnitude of the increase in willingness to pay (WTP) for improvements in the water rights system thus reveals the inefficiency of the current system.

Focussing on smallholder irrigators in South Africa, this study economically values improvements in the definition of the current water rights system. This is relevant because the system has recently received quite some criticism [8-10]. The focus on smallholder irrigators is appropriate in South Africa, because their water use efficiency is low [11] and cost-recovery of government investments in these schemes is a well-known problem $[8,12]$. Improved water rights will not only stimulate smallholders to use water more productively [2, 13], it will also allow governments to increase water prices and thus improve cost recovery.

To analyse the WTP of smallholder farmers for changes in the water rights system contingent ranking (CR), a form of choice experiment, is used in this study. CR is a survey-based technique for modelling preferences for goods, where goods are described in terms of their attributes and the level these take. Various alternative descriptions of a good, differentiated by their attribute levels, are presented to the respondents and they are asked to rank the various alternatives. By including price as one of the attributes of the good, WTP can be indirectly calculated from people's rankings [14]. In a second step the sampled smallholder population was stratified to evaluate the impact of smallholder characteristics on their WTP.

\section{Water rights system in South Africa}

In South Africa the National Water Act replaced the previous system of water rights and entitlements, which was based on the ownership of riparian land, with a new system of administrative limited-period and conditional authorizations to use water [9]. This change in water rights system must be seen in the context of the efforts since 1994 of the new democratic government to overcome the legacy of the apartheid system by restructuring the constitution, legal system, policies and institutions [15]. Currently a process of licensing of existing and potential new water users is carried out progressively in the different parts of the country [16]. In practice the responsible water management authority issues a notice calling for license applications, after which users and prospective users should prepare and submit such applications [16]. 
Several authors have already identified shortcomings in the new water rights system. Backeberg [8] described how a short review period of licenses has a negative effect on farmers' investment decisions. Currently a five years review period is installed to allow government to take timely measures to maintain the integrity of the water resource, achieve a balance between available water and water requirements, or accommodate changes in water use priorities [16]. However, the fact that conditions attached to licenses may change at each review (for instance the volumes and timing of abstractions, the volume that may be stored etc...) gives farmers the impression that licences are insecure [9]. Nieuwoudt and Armitage [9] furthermore pointed out that the reliability of allocation is impeded because there is no guaranteed supply. Indeed, an important aspect of the water licenses in South Africa is that although quantities will be specified in the license, they are not guaranteed. This has a negative effect on the quality of the title because the capacity of the title to adequately describe the resource is limited. Louw and Van Schalkwyk [10] finally have criticized the provisions made in the National Water Act regarding transferability. Transferable water rights and water markets are generally believed to improve water productivity through the transfer of water from low value users to high value users $[9,17]$. However in South Africa permanent transfers, constituting trade in water use authorizations, will be subject to all requirements for license applications. This means that the water management agency has to approve every transfer. For transfers of water rights among irrigators at a same irrigation scheme this type of administrative procedure seems to create unnecessary transaction costs and insecurity, limiting efficiency gains from such water transfer. In addition, legislation is not very clear about the introduction of these arrangements and the conditions under which trade will be permitted $[8,18]$.

\section{Methodology}

In this study a CR experiment is developed to determine willingness to pay for improvements in the water rights system. The technique is originating from marketing and transportation science, but recently choice models, of which CR is a special form, have proven to be useful in valuing multidimensional interventions in a system [14, 19-22]. The technique enables to value both the whole intervention as its individual components. An advantage of $\mathrm{CR}$ is the avoidance of an explicit elicitation of respondents' willingness to pay by relying instead on the ranking of a series of alternative packages of characteristics [14, 20]. Moreover CR is a relative informational efficient method compared with for instance binary choice models, $[23,24]$. Possible problems in using the method are the complex nature of the statistical design, the selection of the appropriate attributes and levels and the cognitive difficulty associated with ranking choices [14]. Typically the design of a choice experiment involves three key stages [23, 25]. First the problem has to be characterised. This was done in the first two sections of this paper. Then the attributes and their levels should be chosen. Researchers must be careful that the attribute space is constructed in a way 
relevant for the policy questions being asked. Finally experimental design procedures are used to construct the choice tasks that will be presented to the respondents. The next paragraphs discuss the implementation of the two last steps in this study.

\subsection{Design of the attribute space}

An influential approach to analyse rights to natural resources categorizes six dimensions: duration, exclusivity, quality of title, flexibility, transferability and divisibility of rights [26]. Such subdivision highlights how attributes of rights may be adjusted separately along various dimensions, specifying rights (and implicitly leaving other attributes of rights undefined). As was shown by Challen [3] and Crase and Dollery [27], this deconstruction can also be applied to water rights. In order to keep the size of the CR experiment within manageable proportions only the most relevant dimensions for the case of South Africa were included. These dimensions were identified based on a literature review. Duration, transferability and quality of title were selected because in literature some degree of attenuation is reported for these dimensions [8-10, 18]. Implicitly it is assumed that the lack of criticism on the other dimensions implies that these are at present already fairly efficient. Table 6.1 provides an overview of the attributes and attribute levels considered.

Table 1: $\quad$ Attributes and levels used in the choice sets.

\begin{tabular}{|c|c|c|c|}
\hline Attributes & \multicolumn{3}{|c|}{ Levels } \\
\hline Transferability & not transferable & agency based transfer & market transfer \\
\hline Duration & 5 year & 10 year & \\
\hline Quality & guaranteed quantity & quantity not guaranteed & \\
\hline Price & $6 \mathrm{c} / \mathrm{m}^{3}$ & $9 \mathrm{c} / \mathrm{m}^{3}$ & $12 \mathrm{c} / \mathrm{m}^{3}$ \\
\hline
\end{tabular}

In terms of duration the National Water Resources Strategy Paper of South Africa [16] foresees a water license that has to be evaluated at least every 5 years. Levels for the duration attribute in this study are therefore set at 5 years, which is regarded as base situation, and 10 years. The 10 years level was chosen here because this is considered long enough not to deter most investments, while still allowing government to respond relatively fast to changing circumstances. In the CR experiment three levels were introduced to assess the importance of transferability: no possibility to transfer, administrative transfer and market transfer. As explained in section 2, the administrative transfer option reflects the current provisions made in the National Water Act. In addition, because of the legal uncertainty it was also considered relevant to include the option of nontransferable water rights in the experiment. The dimension of quality of title encompasses the capacity of the title to adequately describe the resource or item. As levels for the quality of title dimension, "no guaranteed" and "guaranteed supply" were chosen in this study. Finally, to be able to economically value attribute changes, a pricing vehicle was included. We use the unit price of water $\left(\mathrm{R} / \mathrm{m}^{3}\right)$ to evaluate respondent's WTP for the changes in the different attributes. The price attribute is set at three levels $0.06,0.09$ and $0.12 \mathrm{R} / \mathrm{m}^{3}$. The price of 
$0.06 \mathrm{R} / \mathrm{m}^{3}$ corresponds to the order of magnitude of the water prices in the study area. Because the value attached to the improvements should only capture part of the value of water, the range is also well below most estimations of the productive value of water, which usually lie above $0.5 \mathrm{R} / \mathrm{m}^{3}$ [28].

\subsection{Design of the ranking sets}

The full factorial design or all possible combinations of four attributes, two with two different levels and two with three different levels constitute 36 water right definitions. Clearly, it would not be feasible to ask respondents to rank 36 options. Consequently, it was necessary to group the options into smaller sets $[24,25]$. This was done in three stages. In the first stage an orthogonal design was constructed using the Orthoplan-function in Spss. Such orthogonal design allows isolating the effects of individual attributes on the choice, also called the main effects. In our experiment the orthogonal design resulted in nine options. Because ranking nine options was still considered unfeasible, it was decided to limit the number of options to be ranked to four in the second stage. To construct a set of four options a procedure developed by Street et al. [29] is used. The basic idea of the construction technique is simple: the options from the orthogonal design will represent the first option in the choice sets; then a systematic set of level changes is applied to obtain the second option in the choice sets; and another systematic set of changes is applied to get the third option, and so on. Starting from the orthogonal design, nine choice sets consisting of four options were obtained. The choice sets constructed in this way have desirable properties such as minimum attribute-level overlap and balance, allowing more information to be gathered from the same sample [29]. In the final stage, following Holmes and Adamowicz [23], it was decided to divide the choice sets in blocks to avoid the respondents' fatigue effect. Each respondent is assigned randomly to a particular block. Three blocks of three choice sets were constructed. Figure 1 presents a choice set. A graphical representation of the attribute levels was used because part of the respondent population was expected to be illiterate.

\subsection{Data collection}

The data were collected in April 2008 in the Limpopo province of South Africa. Two regions with clusters of smallholder irrigation schemes were selected: the region around Mafefe and the region around Trichardtsdal. Although geographically close to each other these regions are separated by an embranchment of the Drakensbergen mountain range. The difference in cropping patterns between the regions reflects the degrees of water scarcity. Within these regions seven irrigation schemes were identified from the national database of small-scale irrigation schemes. Both larger irrigation schemes with over 100 farmers and smaller schemes with only 30-40 farmers were included in the sample. In this way a sample exemplary for the situation of smallholder irrigation schemes in the rural areas of South Africa was established. 


\begin{tabular}{|c|c|c|c|c|}
\hline Attributes & Option 1 & Option 2 & Option 3 & Option 4 \\
\hline & $\frac{1}{x}$ & & $t$ & 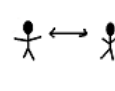 \\
\hline Duration & 5 years & 10 years & 10 years & 5 years \\
\hline Quality of title & & & ???? & ???? \\
\hline Price & $12 \mathrm{c} / \mathrm{m}^{3}$ & $6 \mathrm{c} / \mathrm{m}^{3}$ & $9 \mathrm{c} / \mathrm{m}^{3}$ & $12 \mathrm{c} / \mathrm{m}^{3}$ \\
\hline Rank & & & & \\
\hline
\end{tabular}

Figure 1: Choice set example.

Contacts with the scheme management were made through the extension services responsible for the schemes. About $30 \%$ of the farmers were randomly selected from a list of active farmers. Before starting the questionnaire the objective of the study was explained and respondents were given information regarding the actual water rights system. In a stepwise manner, they were made familiar with the graphical representation of the attribute levels included in the $\mathrm{CR}$ experiment. Besides the $\mathrm{CR}$ experiment, the questionnaires also included detailed information regarding farming activities, alternative income sources and institutional aspects of water management. In total 134 questionnaires were completed, which provided 402 choice sets for analysis.

\subsection{Analytical framework}

The econometric analysis of data collected from a CR experiment is based on McFadden's conditional logit model, which is grounded in the random utility framework. The indirect utility function $\mathrm{U}_{\mathrm{ij}}$ is decomposed in two parts (eq. (1)): an observable element $b\left(X_{i j}, Z_{i}\right)$ which describes the preferences of respondent $i$ as a function of the attributes of the alternatives presented to the individual $X_{\mathrm{ij}}$ and the characteristics of the individuals $Z_{\mathrm{i}}$ and secondly a stochastic element $\varepsilon_{\mathrm{ij}}$, which represents those influences on individual choice that cannot be observed by the researcher.

$$
\mathrm{U}_{\mathrm{ij}}=\mathrm{b}\left(\mathrm{X}_{\mathrm{ij}}, \mathrm{Z}_{\mathrm{i}}\right)+\varepsilon_{\mathrm{ij}}
$$

Typically it is assumed that the $\varepsilon_{\mathrm{ij}}$ are independently and identically distributed with an extreme-value (Weibull) distribution, resulting in a conditional logit model. Because a conditional logit model only allows the identification of the most preferred alternative and thus not fully exploits all the information contained in the CR experiment Beggs et al. [30] developed an extension to the basic conditional logit model. This extension, known as the rank-ordered logit model is capable of not only identifying the most preferred alternative but also the exact ordinal ranking of all of the remaining elements. In 
the model the probability of obtaining a particular ranking can be expressed as shown in eq. (2) [31].

$$
\mathrm{P}\left(\mathrm{U}_{\mathrm{i} 1}>\mathrm{U}_{\mathrm{i} 2} \quad \ldots>\mathrm{U}_{\mathrm{ij}}\right)=\prod_{j=1}^{J} \frac{\exp \left(b X_{i j}\right)}{\sum_{k=j}^{J} \exp \left(b X_{i k}\right)}
$$

Once the parameter estimates of this model have been obtained, a WTP compensating variation welfare measure that is conform to demand theory can be derived for each attribute [14]. When it is assumed that utility is a linear function of the attribute levels like in equation 1, WTP can simply be expressed as:

$$
W T P=\frac{-b_{c}}{b_{y}}
$$

where $b_{y}$ is the coefficient of the cost attribute and $b_{c}$ is the coefficient of any of the attributes. Equation 3 corresponds to the marginal rate of substitution between the price attribute and the other attribute in the equation and is technically called the implicit price. By comparing this WTP for different strata in the population, the impact of smallholder characteristics on their WTP can be assessed.

\section{Results and discussion}

\subsection{Rank ordered logit results}

The results of the rank ordered logit models were obtained using the statistical package STATA version 9. Following the recommendations of Holmes and Adamowicz [23] qualitative attributes were effect coded. When using effect coding, the base level is assigned code -1 . For the quality of title dimension "no guaranteed supply" was the base level, while for the transferability the base level was "no possibility to transfer". In the interpretation of the results, this base level takes the utility level of the negative of the sum of the other estimated coefficients, and the other levels take the utilities associated with their coefficient. Table 2 presents the rank ordered logit estimates. All the coefficients are significantly different from zero at a $1 \%$ significance level, meaning that they all are significant determinants of choice. The signs of the attribute parameters are as expected. Guarantee of water supply, increased duration of the license and improvements in transferability all increased the probability that an option was chosen. Oppositely, a higher water price decreased the choice probability. This is also reflected in the odds ratios and the derived percentage change in odds, which reflect the difference in chance of choosing a particular option when the attribute changes. For the average respondent, quality of title and market transfer is the most important attributes.

The population was stratified in table 3 , table 4 and table 5 . In table 3 model results are compared for respondents who experience water shortages (and have reduced cultivated area in the dry season by more than $25 \%$ ) and respondents who did not experience water shortages (no reduction in cultivated area). Results 
for the remaining group of farmers are not reported because this group with 16 cases was too small to yield reliable results. The chance of choosing a water right option with assured water supply is clearly much higher for farmers experiencing water shortages, compared to those who do not experience shortages. In addition for farmers experiencing shortages, market transfer is more important as determinant of choice, probably because they see this as a way of ensuring water supply.

Table 2: $\quad$ Rank ordered logit model results (full sample $\mathrm{n}=134$ ).

\begin{tabular}{|l|l|l|l|l|}
\hline Attributes & Coefficient & Odds ratios & \% change in odds & p-value \\
\hline Duration & 0.096 & 1.100 & 10 & 0.000 \\
\hline Quality of title & 0.628 & 1.875 & 87.5 & 0.000 \\
\hline Agent based transfer & 0.230 & 1.259 & 25.9 & 0.000 \\
\hline Market transfer & 0.360 & 1.433 & 43.3 & 0.000 \\
\hline Price & -0.048 & 0.953 & -4.7 & 0.001 \\
\hline
\end{tabular}

Table 3: $\quad$ Rank ordered logit model results for strata with different levels of water shortage.

\begin{tabular}{|l|l|l|l|l|l|l|}
\hline & \multicolumn{3}{|l|}{ No water shortage $(\mathbf{n}=\mathbf{3 6})$} & \multicolumn{3}{l|}{ Water shortage (n=82) } \\
\hline Attributes & coeff & $\begin{array}{l}\text { Odds } \\
\text { ratio }\end{array}$ & $\begin{array}{l}\% \text { change } \\
\text { odds }\end{array}$ & coeff & $\begin{array}{l}\text { Odds } \\
\text { ratio }\end{array}$ & $\begin{array}{l}\text { \%-change } \\
\text { odds }\end{array}$ \\
\hline Duration & $0.093^{*}$ & 1.097 & 9.7 & $0.092^{*}$ & 1.097 & 9.7 \\
\hline Quality of title & $0.499^{*}$ & 1.647 & 64.7 & $0.672^{*}$ & 1.959 & 95.9 \\
\hline $\begin{array}{l}\text { Agent based } \\
\text { transfer }\end{array}$ & $0.301^{*}$ & 1.352 & 35.2 & $0.247^{*}$ & 1.280 & 28.0 \\
\hline $\begin{array}{l}\text { Market } \\
\text { transfer }\end{array}$ & $0.210^{* *}$ & 1.233 & 23.3 & $0.471^{*}$ & 1.602 & 60.2 \\
\hline Price & $-0.054^{* *}$ & 0.947 & -5.3 & $-0.052^{*}$ & 0.950 & -5.0 \\
\hline
\end{tabular}

** significant at $0.05 \%$; $*$ significant at $0.01 \%$

Table 4: Rank ordered logit model results for strata with different institutional trust levels.

\begin{tabular}{|l|l|l|l|l|l|l|l|l|l|}
\hline & \multicolumn{3}{|l|}{ Low trust (n=48) } & \multicolumn{3}{l|}{ Medium trust (n=45) } & \multicolumn{3}{l|}{ High trust (n=41) } \\
\hline Attributes & coeff & Odds & \% & coeff & Odds & \% & coeff & Odds & $\%$ \\
\hline Duration & $0.093^{*}$ & 1.098 & 9.8 & $0.088^{*}$ & 1.087 & 8.7 & $0.105^{*}$ & 1.110 & 11 \\
\hline $\begin{array}{l}\text { Quality of } \\
\text { title }\end{array}$ & $0.798^{*}$ & 2.221 & 122.1 & $0.628^{*}$ & 1.875 & 87.5 & $0.479^{*}$ & 1.615 & 61.5 \\
\hline $\begin{array}{l}\text { Agent } \\
\text { based } \\
\text { transfer }\end{array}$ & 0.046 & 1.047 & 4.7 & $0.236^{*}$ & 1.267 & 26.7 & $0.481^{*}$ & 1.618 & 61.8 \\
\hline $\begin{array}{l}\text { Market } \\
\text { transfer }\end{array}$ & $0.252^{*}$ & 1.286 & 28.7 & $0.392^{*}$ & 1.480 & 48.0 & $0.458^{*}$ & 1.581 & 58.0 \\
\hline Price & $-0.084^{*}$ & 0.920 & -8 & -0.028 & 0.973 & -2.7 & -0.028 & 0.972 & -2.8 \\
\hline
\end{tabular}

* significant at $0.01 \%$

Table 4 illustrates the importance of institutional trust. On the one hand, for farmers with low institutional trust (36\%) mainly the quality of the title is of importance, while introduction of agency-based transfer hardly increases the odds. If institutional trust is high on the other hand (31\%), the fact of having a 
system with agency-based transfer is considered as important as the quality of the title. For water transfer options to be successful it appears thus important that trust in institutions is improved. An important aspect here is communication; farmers know at this moment insufficiently how the water management institutions work and what their responsibilities are.

The impact of the income contribution of irrigation on the preferences of farmers is shown in table 5. If the income from irrigation constitutes only a small part of the total family income $(<20 \%)$ then a unit price increase should only have a minor impact on the odds of choosing an option. When irrigation contributes for more then $35 \%$ to the family income, the negative effect is about 3 times larger. This was expected, because farmers depending more on irrigation generally have a lower total income. Because their income would be more affected by insufficient supply, also quality of the title is much more important for farmers depending more on irrigation compared to the other group.

Table 5: $\quad$ Rank ordered logit model results for strata with different income contribution of irrigation.

\begin{tabular}{|l|l|l|l|l|l|l|}
\hline & \multicolumn{4}{|l|}{ Low income contribution (n=63) } & \multicolumn{3}{l|}{ High income contribution $(\mathbf{n}=\mathbf{4 0})$} \\
\hline Attributes & coeff & Odds & \% & Coeff & Odds & \%- \\
\hline Duration & $0.116^{*}$ & 1.123 & 12.3 & $0.094^{*}$ & 1.098 & 9.8 \\
\hline Quality of title & $0.575^{*}$ & 1.778 & 77.8 & $0.793^{*}$ & 2.210 & 121 \\
\hline $\begin{array}{l}\text { Agent based } \\
\text { transfer }\end{array}$ & $0.172^{*}$ & 1.188 & 18.8 & $0.201^{* *}$ & 1.223 & 22.3 \\
\hline $\begin{array}{l}\text { Market } \\
\text { transfer }\end{array}$ & $0.410^{*}$ & 1.507 & 50.7 & $0.355^{*}$ & 1.426 & 42.6 \\
\hline Price & $-0.036^{* * *}$ & 0.965 & -3.5 & $-0.121^{*}$ & 0.886 & -11.4 \\
\hline
\end{tabular}

*** significant at the $0.1 \%$; significant at $0.05 \%$; * significant at $0.01 \%$

Table 6: Implicit values of attributes changes for different strata.

\begin{tabular}{|l|l|l|l|l|l|l|l|l|}
\hline \multirow{2}{*}{$\begin{array}{l}\text { Attribute } \\
\text { changes }\end{array}$} & \multicolumn{7}{|c|}{$\begin{array}{l}\text { Full } \\
\text { sample }\end{array}$} & \multicolumn{2}{|l|}{$\begin{array}{l}\text { Water } \\
\text { shortage }\end{array}$} & \multicolumn{2}{|c|}{ Institutional trust } & \multicolumn{2}{|l|}{$\begin{array}{l}\text { Income } \\
\text { contribution }\end{array}$} \\
\cline { 2 - 9 } & & No & Yes & Low & Medium & High & Low & High \\
\hline $\begin{array}{l}\mathbf{5} \text { years to 10 } \\
\text { years }\end{array}$ & 9.7 & 8.6 & 8.8 & 5.5 & 15.7 & 18.8 & 16.1 & 3.9 \\
\hline $\begin{array}{l}\text { Securing } \\
\text { supply }\end{array}$ & 12.6 & 9.2 & 12.9 & 9.5 & 22.4 & 17.0 & 16.0 & 6.6 \\
\hline $\begin{array}{l}\text { No transfer to } \\
\text { agency based } \\
\text { transfer }\end{array}$ & 14.6 & 15.0 & 18.6 & 4.0 & 30.9 & 50.7 & 20.9 & 6.3 \\
\hline $\begin{array}{l}\text { Agency based } \\
\text { transfers to } \\
\text { market } \\
\text { transfer }\end{array}$ & 2.4 & -1.7 & 4.3 & 2.5 & 5.6 & -1.0 & 6.6 & 1.3 \\
\hline
\end{tabular}

A major purpose of the CR experiment was to obtain the implicit values of marginal attribute changes. Table 6 presents the estimates of the implicit prices derived for the entire sample and for different strata. The results on the full sample indicate that securing supply and the opportunity to transfer water 
licenses are highly valued. Installing water markets does not seem to add much value compared with a system of agency-based transfer. When comparing different strata, following results catch the eye: Farmers experiencing water shortages are not only willing to pay more for secured supply, but also for improved transferability of water rights; WTP of farmers with low institutional trust is clearly lower for all attribute changes then that of those with medium or high institutional trust; similarly WTP of poorer farmers (those who depend more on irrigation) is also lower for all attribute changes.

\section{Conclusions}

As competition for water grows across the globe, water users and water management organizations seek better institutional arrangements for coordinating use and resolving conflicts [2]. Improved water rights are one option to increase water productivity, to raise benefits from existing and new investments in water use and enhance rural livelihoods. This study demonstrates how $\mathrm{CR}$ can be used to measure the extent to which water rights can be improved along different dimensions and how different strata of the population perceive such improvements. The study is applied to the case of smallholder irrigators in South Africa. The results of the rank ordered logit model using the full sample indicate that for the smallholders, there are significant economic gains attached to the improvement of the water rights. Especially the possibility to transfer and the assurance of supply are highly valued. These average results however mask large differences between different strata in the population. Farmers experiencing water shortage have a higher WTP for secured supply and for improved transferability of water rights. These farmers see improvements in the water rights system as potential solutions for their water shortage problem. The analysis of the importance of institutional trust indicates that trust in the institutions is necessary to fully value water rights improvements. This implies that from a cost recovery perspective it is important for the government to increase the trust of small-scale farmers in the water management institutions, since this will increase their WTP for the interventions. Finally, as expected the poorer farmers in the sample, which are more dependent on irrigation for their income, have a strong negative attitude against price increases. This limits their WTP for water rights improvements. From the above, it is clear that the results presented in this paper offer valuable insights to policy makers to guide water right reforms.

\section{References}

[1] Matthews OP (2004) Fundamental questions about water rights and market reallocation. Water Resources Research 40. DOI:10.1029/2003WR002836

[2] Bruns B, Ringler C, Meinzen-Dick R (2005) Water Rights Reform: Lessons for Institutional Design, IFPRI, Washington, USA

[3] Challen R (2000) Institutions, Transaction Costs, and Environmental Policy: Institutional Reform for Water Resources. Edward Elgar, Cheltenham, UK 
[4] Heltberg R. (2002) Property Rights and Natural Resource Management in Developing Countries. Journal of Economic Surveys 16: 189-214

[5] Linde-Rahr M (2008) Willingness to Pay for Forest Property Rights and the Value of Increased Property Rights Security. Environ Resource Econ (in press). DOI 10.1007/s10640-008-9202-3

[6] Herrera P, Van Huylenbroeck G, Espinel R (2004) An application of the contingent valuation method to assess the efficiency of the institutional structure of irrigation property rights: the case of the Peninsula of Santa Elena. International Journal of Water Resource Development 20(4): 537551

[7] Frija A, Chebil A, Speelman S, Van Huylenbroeck G (2008) Effect of changes in the institutional structure of irrigation water property rights on the willingness to pay of farmers for water. In: Proceedings of the XIIth EAAE Congress: People food and environments: global trends and European strategies, Ghent, Belgium, 26-29 August 2008

[8] Backeberg G (2006) Reform of user charges, market pricing and management of water: problem or opportunity for irrigated agriculture? Irrigation and Drainage 55: 1-12

[9] Nieuwoudt WL, Armitage RM (2004) Water market transfers in South Africa: Two case studies. Water Resources Research 40. DOI:10.1029/2003WR002840

[10] Louw DB, van Schalkwyk HD (2002) Efficiency of water allocation in South Africa: Water markets as an alternative. Paper presented at the Irrigation Water Policies: Micro and Macro Considerations Conference, Agadir, Morocco, 15-17 June 2002

[11] Speelman S, D'Haese M, Buysse J et al (2008a) A measure for the efficiency of water use and its determinants, study at small-scale irrigation schemes in North-West Province, South Africa. Agricultural Systems 98(1): 31-39

[12] Perret S, Geyser M (2007) The cost of irrigation: adapting existing guidelines to assess the full financial costs of irrigation services. The case of smallholder schemes in South Africa. Water SA 33: 67-78

[13] Bruns B (2007) Irrigation water rights: options for pro-poor reform. Irrigation and drainage 56: 237-246

[14] Hanley N, Mourato S, Wright R (2001) Choice modelling approaches: a superior alternative for environmental valuation. Journal of economic surveys 15: 435-462

[15] Wester, P., Merrey, D., de Lange, M. (2003). Boundaries of consent: Stakeholder representation in river basin management in Mexico and South Africa. World Development, 31, 797-812

[16] DWAF (2004) National Water Resources Strategy Paper of South Africa. Department of Water Affairs and Forestry, Republic of South Africa

[17] Zekri S, Easter KW (2007) Water reforms in developing countries: management transfers, private operators and water markets. Water Policy 9(6): 573-589 
[18] Perret S (2002) Water policies and smallholding irrigation schemes in South Africa: A history and new institutional challenges. Water Policy 4(3): $283-300$

[19] Hanley N, Wright RE, Adamowicz VL (1998) Using Choice Experiments to Value the Environment. Environmental and Resource Economics 11(34): 413-428

[20] Bateman IJ, Cole MA, Georgiou S et al (2006) Comparing contingent valuation and contingent ranking: a case study considering the benefits of urban river water quality improvements. Journal of environmental management 79: 221-231

[21] Hanley N, Colombo S, Tinch D et al (2006) Estimating the benefits of water quality improvements under the Water Framework Directive: are benefits transferable? European Review of Agricultural Economics 33 (3): 391-413.

[22] Burton M, Marsh S, Patterson J (2007) Community attitudes towards water management in the Moore Catchment, Western Australia. Agricultural systems 92: 157-178

[23] Holmes TP, Adamowicz VL (2002) Chapter 6: Attribute based methods. In: Boyle KJ, Champ PA (eds) A primer on non-market valuation. Kluwer Academic Publishers, Boston

[24] Alriksson S, Öberg T (2008) Conjoint Analysis for Environmental Evaluation A review of methods and applications. Env Sci Pollut Res 15: 244-257

[25] Bennett J, Adamowicz V (2001) Some fundamentals of environmental choice modeling. In Bennett J, Blamey R (eds) The choice modelling approach to environmental valuation. Edward Elgar, Cheltenham, UK

[26] Bruns B (2006) Reconstituting Water Rights: Pathways for Polycentric Praxis. Paper presented at Survival of the Commons: Mounting Challenges and New Realities, International Association for the Study of Common Property, Bali, Indonesia, 19-23 June 2006

[27] Crase L, Dollery B (2006) Water rights: a comparison of the impacts of urban and irrigation reforms in Australia. The Australian Journal of Agricultural and Resource Economics 50: 451-462

[28] Speelman S, Farolfi S, Perret S et al (2008b) Irrigation water value at small-scale schemes: evidence from the North-West Province, South Africa. International Journal of Water Resources Development 24(4): 621633

[29] Street DJ, Burgess L, Louviere J (2005) Quick and easy choice sets: Constructing optimal and nearly optimal stated choice experiments. Intern. Journal of Research in Marketing 22: 459-470

[30] Beggs S, Cardell S, Hausman J (1981) Assessing the potential demand for electric cars. Journal of econometrics 16: 1-19

[31] Hanemann WM, Kanninen B (1999) Statistical analysis of discreteresponse CV data. In: Bateman IJ, Willis KG (eds) Valuing Environmental Preferences: Theory and Practice of the Contingent Valuation Method in the US, EU, and Developing Countries. Oxford University Press 